\title{
The open long tail model between new culture and digital technology
}

\author{
PAOLA PISANO MARCO PIRONTI ${ }^{* *}$ IOANNIS P. ChRISTOdOULOU***
}

\begin{abstract}
Purpose of the paper: The aim of this paper is to describe an emerging business model that comes from the digitization of the world of tangible products.

Methodology: The creation of niche products, their production and sales in an open business model is analyzed through the literature review of bth models and sustained by the analysis of practice cases.

Findings: This new business model, defined by the authors as the open long tail model, includes the features of both the open business model and the long tail model because it sustains the collaborative trend of the web generation and creates a large number of niche, physical things rather that "just pixels on screens".

Research limits: Given its focus on the empirical evidence from the diffusion of new digital and flexible technologies, our analysis has identified a new trend in the manufacturing industry business model that seems to have a positive effect on the organization as well as the customer.

Practical implications: The future of this emerging business model looks promising thanks to its democratization of creativity and manufacturing trajectory and its capability to create more revenue for anyone willing to undertake this venture.

Originality of the paper: This new stream of creativity, democratization and innovation is possible thanks to the open long tail model based on the new user that wants to make objects, the emergence of digital tools for design and production, the collaboration between actors.

Key words: accessibility; feasibility; manufacturing industry; open business model;3-D printing
\end{abstract}

\footnotetext{
* Professore Aggregato di Economia e Gestione delle Imprese - Università degli Studi di Torino

e-mail: pisano@di.unito.it

** Associato di Economia e Gestione delle Imprese - Università degli Studi di Torino e-mail: pironti@di.unito.it

*** Senior Lecturer in Business Strategy - Westminster University e-mail: I.Christodoulu@westminster.ac.uk
} 


\section{Introduction}

Living with global instability and uncertainty is fast becoming a way of life for organizations. While some corporations seem to respond reactively and revert back to fixed strategies, resisting change, using high control whilst basing their business on fixed and standard business models, others seem to be more open to accept and embrace change. These organizations are looking for possibilities and opportunities that may somehow exist within this chaos and disorder, by seeking to contribute and collaborate towards creating business models and strategies to proactively deal and work with the speed of change and globalization. Within this framework new businesses are being established that base their model on the culture of sharing new ideas, on the ability to raise collaborations in order to build the skills and resources needed to fulfill, grow and develop their aims. An example of the category of these new ventures is provided by those internet platforms that gather, collect and sell ideas and concepts 'posted' by external designers and consumers, using crowdsourcing resources to select the right concept, building up the idea and raising funds to produce it. Finally the electronic version of the idea takes shape through powerful software tools such as the 3-D printer manufacturing process. These new technologies accelerate an innovative approach to the manufacturing industry whilst decreasing the limitation of physical constrains and helping the creation of a more economically attractive business model. The digital manufacture allows to produce different, innovative and customized products and to respond to the dynamism of a competitive environment. This technology expands the number of products available and thanks to digital distribution is easily reachable by customers. The trend is in line with a new culture and economy that are shifting away from a focus on a relatively small number of hits and moving toward a huge number of niches. The above tendency is amplified by another tendency defined as a "true economic force" (Anderson, 2013), the "maker movement", a term first coined by Dougherty of O'Reilly Media in 2005, describing a web generation that creates physical things rather than just pixels on screens. The MIT Media Lab defines the maker movement as people that are "treating atoms like bits using the powerful tools of the software and information industries to revolutionize the way we make tangible objects" (Anderson, 2013). While new digital tools enable product flexibility, the internet platform model gives companies the opportunity to collaborate and decrease physical constraints like shelf space and other bottlenecks of distribution. The aim of this paper is to advance a set of propositions that will boil down to an innovative business model emerging from a new culture and technology and sustained through three practice cases.

\section{Literature review}

In this paragraph the authors analyse the literature review on the open business model and long tail model from which the open long tail model can be seen to emerge. 


\subsection{The open business model}

An open system model is a model in which the firm creates and captures value to take advantage of both internal and external resources. In his book "Open Business Model: How to Thrive in the Innovation Landscape”, Chesbrough (2006a) analyzed the characteristics that a firm should exhibit to create an open organization.

According to the author, indeed, in the old model of "closed organization", companies had to generate their own ideas that they would then develop, manufacture, market, distribute and service themselves.

The open organization model involves organizational characteristics that are suitable for managing creative innovations, including the process of acquiring and integrating new ideas into the organization and marketing them. As "valuable ideas can come from inside or outside the company and can go to market from inside or outside the company as well" (Chesbrough, 2006b), in the open organization model, firms commercialize external (as well as internal) ideas by deploying outside (as well as in-house) pathways to the market. Specifically, companies can commercialize internal (external) ideas through channels outside (inside) of their current businesses to generate value for the organization.

The vehicles for accomplishing this goal are contingent upon the organization's ability to create connections with external actors to absorb different types of knowledge (Ahuja, 2000), improve survival rates (Baum and Oliver, 1991), increase innovativeness (Baum et al., 2000; Stuart, 2000), improve performance (Hagedoorn and Schakenraad, 1994; Shan et al., 1994) and grow faster in general (Powell et al., 1996; Stuart, 2000).

Many are the organizations structured according to an open model: for example, InnoCentive, an Eli Lilly spin-off, manages a platform where organizations can post their unsolved technical issues and the scientific community addresses them by using the internal R\&D of the pharmaceutical organizations; Fold. it, a revolutionary new computer game enabling everyone to contribute to important scientific research.

Business model innovation literature, instead, is not so robust, and the main references relate to fast-paced technology sectors and services. Here, different contributions highlight how business models change by leveraging and engaging external partners as co-developers (Chesbrough and Schwartz, 2007). According to this dominant frame, even customers become productive collaborative partners, codevelopers (McKelvey, 2001) or sources of innovation (Cherbrough, 2006a), changing the essence of the company and, in some cases, the company's business logic that traditionally regarded customers as mere buyers.

The vision that business model innovation occurs when changes are made in the ways to conduct transactions, to create and deliver value and to build up new customer relationships is indeed widely accepted. Especially in service sectors and in the fast-paced technology industry, different business model innovations have been conceived, reconfiguring the customer's role in the productive process.

The dominant innovation directions that have been pursued so far involve the customer's role as a collaborative producer (McKelvey, 2001; Pisano and Verganti, 
2008; Johnson et al., 2008). The advent of a user-generated content movement, the diffusion of social media and Web 2. 0 technologies, and the emergence of skilled and well-educated customers has enabled whole crowds or single users to heavily collaborate in the production processes of companies. According to this framework, the customer is a company productive or co-developing partner that jointly affects the evolution, the costs and the benefits of the business ecosystem.

The co-design model of innovation (Prahalad and Ramaswamy, 2004) goes beyond traditional involvement of end users through qualitative research (focus group, in deep interviews etc. ) and it is based upon customers' engagement on idea generation and products development.

The inclusion of end users in the design process of new products and services is not new for design discipline and, as such, it has been debated for a long time in management and marketing literature. This multifocal viewpoint has brought to a proliferation of labels and definitions, from co-design as a new design method (Binder and Brandt, 2008); to open-innovation (Von Hippel, 2009); to participatory design (Ehn, 2005).

\subsection{The long tail model}

The long tail concept was coined by Chris Anderson (2006) to describe a shift in the media business from selling a small number of "hit" items in large volumes toward selling a very large number of niche items each in relatively small quantities. Anderson (2006) believes that the three economic riggers that gave rise to this phenomenon in the media industry are the following:

- the democratization of tools of production: falling technology costs have given individuals access to tools that were prohibitively expensive just a few years ago. Millions of passionate amateurs can now record music, produce short films, design simple software with professional results and create object with 3-D printer technology;

- the democratization of distribution: the Internet has made digital content distribution a commodity and dramatically lowered inventory, communications and transactions costs, opening up new markets for niche products;

- falling search costs to connect supply with demand: the real challenge of selling niche content is now to find interested potential buyers. Powerful search and recommendation engines, user ratings and communities of interest have made this much easier.

For a number of product categories smart technology is transforming the mass market into millions of small niche markets. Although each of these niche markets may be small, when all the various niches are combined together business volume is actually greater than traditional mass market successes. However, the offer alone of more variety does not seem able to generate greater demand. Instead consumers need to have tools that will help them find product niches which match their tastes and interests. These tools need to act as filters by simplifying the finding process. An example of an organization that uses this business model is the online video 
rental company Netflix or Lulu. com, a multi-sided platform that serves and connects authors and readers with the long tail of user-generated niche content.

In the following paragraph the authors describe the methodology and the related practice cases.

\section{Methodology: building propositions through case studies}

Scholars have used case studies to develop theories about topics as diverse as group processes (Edmondson et al., 2001), internal organizations (Galunic and Eisenhardt, 2001; Gilbert, 2005), and strategies (Mintzberg and Waters, 1982). Building theories from case studies is a research strategy that involves using one or more cases to create theoretical constructs, propositions and/or midrange theories from case-based, empirical evidence (Eisenhardt, 1989b). Case studies amount to rich, empirical descriptions of particular instances of a phenomenon characteristically based on a variety of data sources (Yin, 1994).

The scant literature on new forms of entrepreneurship based on creativity and design (Abecassis-Moedas, et al., 2012) lays the foundation for an exploratory research approach that builds propositions and turns them into initial statements to be used as triggers in future research. The central notion in our analysis is to use cases as the basis from which a theory can be inductively developed. The theory emerges from a practical case and is developed by recognizing patterns of relationships in constructs and cases. The theory building process occurs via recursive cycling in the case data, emerging theoryand, lastly, extant literature (Eisenhardt, 1989a; Mintzberg, 1979; Pettigrew, 1988; Yin, 2008). The use of an inductive theory built from cases is relevant especially in the first stage of an analysis because it can produce new theories that are accurate, interesting and testable. This process creates the basis for the second stage of our analysis where data and deductive theory testing complete the cycle.

The selection of practice cases was carried out in line with the criteria of unusually revelatory and extreme exemplars for an atypical research approach, as appropriately underlined by Yin (1994). Moreover, we decided to select not just one case but three different ones because, while single-case studies could richly describe the existence of a phenomenon (Siggelkow, 2007), multiple-case studies would typically provide a stronger basis for theory building (Yin, 1994).

Multiple cases enabled us to compare them to each other and clarify whether an emergent finding was simply idiosyncratic to a single case or consistently replicated by several cases (Eisenhardt, 1991), creating a more robust theory and grounding the propositions in varied empirical evidence. Using multiple cases can delineate constructs and relationships more precisely because it is easier to determine accurate definitions and appropriate levels of construct abstraction from multiple cases. Besides, heory building from multiple cases typically yields more robust, generalizable, and testable theories than single-case research (Eisenhardt and Graebner, 2007). 
As case studies can accommodate a rich variety of data sources we decided to include three semi-structured depth interviews with professors of Technology Management at Stanford University, Westminster University of London and the University of Turin, to view the phenomena from different perspectives and make a more confident selection of the practice cases.

Three practice cases are here investigated. The first case is Quirky, a new venture firm created around the potentials of 3-D printing in order to develop ideas and concepts suggested by designers and users. The second is I-Materialize, an incumbent company specialized in prototyping services that uses 3-D printing to create a digital connection platform between creative communities and users. The third is Fab-Lab, a new global network of design shops based on 3-D printing technology that works with small businesses, users and craftsmen in the production and sales of their products.

In the following paragraphs we will briefly illustrate the three e cases in order to define the information useful to give consistence to the business model explanation.

\section{Quirky}

Quirky is a company of consumer products that turns crowdsourced invention into retail products with a manufacturing process based on 3-D printing technology. Since its launching in 2009, Quirky has rapidly changed the way the world perceives product development.

The process, which goes from an original idea to a final product, involves a significant plethora of different types of actors. Each week different ideas are submitted by dozens of amateurs, such as kitchen workers, technology experts, jewelers, etc..; then, hundreds of online community members (or "Quirks") - mainly composed of hobby inventors, students, retirees and product-design enthusiasts evaluate products and vote for their favorite submissions. The two most popular ideas are sent to an in-house team of engineers and designers to research, render and prototype. Kaufman (Quirky's founder) and his team cull results, sort out potential patent conflicts or production problems, then make the final call on the week's winner. At every stage - design, colors, naming, logo-the community chimes in. The best suggestions are incorporated, earning secondary "influencers" a portion of future sales revenue.

Even when a product gets community approval, it will only make it to market if enough web surfers pre-order it to cover production costs. "This is where we find out if a good idea is a good product", Kaufman says. "The world doesn't need more junk".

In actual fact, less than a third of Quirky's products get made realized. Thanks to the community, Quirky collects a wide range of multi-disciplinary skills needed to turn an idea into something tangible. A background in design, electrical engineering, marketing, fund raising and access to retailers and manufacturers are all required skills for members of the sourcing community in order to complete and sell a 
product. Thus, community members that participate in several aspects of product creation, from design to naming and coming up with a tagline for a piece ("Protect Your Produce" is the Mercado slogan) will receive a small share of the profits.

The manufacturing process includes a small factory with 3-D printers, a laser cutter, milling machines, a spray-painting booth and other bits of equipment. This prototyping shop is central to Quirky's business of turning other people's ideas into products: Quirky's product-development team makes a prototype. Users review this online, contribute towards its final design, packaging and marketing, and help set a price for it. Quirky then looks for suitable manufacturers. The product is sold on the Quirky website and, if demand grows, by retail chains. Quirky also handles patents and standards approvals and gives a 30\% share of the revenue from direct sales to the inventors and others who have helped.

By using its community as a sounding board, Quirky can quickly establish if there is a market for a product and set the right price before committing itself to making it. Moreover, the speed with which Quirky turns designs into products (thanks to 3-D printing technology) is remarkable, "The amount of creativity that happens when you are standing next to a machine that's making hundreds of thousands of things is much greater than when you are working 4,000 miles away", says Mr Kaufman. "Your mind is spinning as to what else you can design for the machine to make".

Kaufman calls this process the "social product development".

"We bring at least three brand new consumer products to market each week, by enabling a fluid conversation between a global community and Quirky's expert product design staff".

The world influences Quirky's business in realtime, and Quirky shares its revenue directly with the people who helped them make successful decisions.

\section{I. Materialize}

I. materialize believes that people have an inherent need to express themselves more than ever before, as nowadays standardization has become the rule. Therefore, I. materialize offers everybody the possibility to turn ideas into 3-D reality.

I. materialize provides demanding designers and inventors with higher quality and greater choice. At the same time, this experience helps organizations make 3-D printing more accessible. With their tools, an increasing number of makers has the opportunity to become designers, inventors producers and sellers.

Born in 1990 as a spin-off of Materialise, I. materialize is an online 3-D printing service which is based in Belgium. First, the service uploads a project file, then it selects material, size and quantity with the aid of a template. Then, a quotation appears and, upon receiving confirmation and an online payment, the product is purchased and delivered. It is also possible to sell the design projects and earn a percentage. 
On the one hand I. materialize gives designers the chance to show their talent and sell their products thanks to a worldwide distribution network, on the other hand potential buyers can access a unique collection of different products built on demand. A set of 3-D software supported by I. materialize is used to create files uploadable to the website: Tinkercad, 3-D Tin, Autodesk 123D and Google SketchUp enable to design some great 3-D printable products without any previous expertise: the maker can just open the browser and start creating in a very intuitive way. Finally, I-Materialize supplies over 20 different 3-D printing materials: common people can sell their design, choose the fee to apply over the production price and manufacture the item in 5 to 15 business days.

\section{Fablab}

A Fab lab (fabrication laboratory) is a small-scale workshop offering (personal) digital fabrication. It is generally equipped with an array of flexible computercontrolled tools that cover several different length scales and various materials, with the aim to make "almost anything". This includes technology-enabled products generally perceived as limited to mass production. Fab labs have already shown the potential to empower individuals to create smart devices for themselves.

The real value of this organization is the model able to diffuse education, business and research appropriate for a world where almost anyone can make almost anything, anywhere. Fab labs share an evolving inventory of core capabilities that allow people and projects to be shared. A fab lab usually includes:

- a computer-controlled lasercutter, for press-fit assembly of 3-D structures from 2D parts;

- a larger (4'x 8') numerically-controlled milling machine, to make furniture- (and house-) sized parts;

- a signcutter, to produce printing masks, flexible circuits, and antennas;

- a precision (micron resolution) milling machine to make three-dimensional molds and surfacemount circuit boards;

- programming tools for low-cost high-speed embedded processors;

- a large number of Fab Labs have opened all over the world from Italy to Spain, from California to Finland.

The Fab Lab pre-college Maker Learning programs for youth in middle and high schools are presented in partnership with the University of California at San Diego. These classes are based on the 'Maker' philosophy that San Diego's Fab Lab has developed in response to the need to inspire students while engaging them in learning next generation technology.

The Fab Lab curriculum includes hands-on, experience-driven activities that are standards based, as well as entertaining and relevant: Fab Lab Fab Foos is an open source Table Soccer Game, opening in Amsterdam and featuring 2 web cams, an audio response, an electronic counter system and VGA out. The Fab Lab House comes from the Institute of Advanced Architecture of Catalonia (IAAC) and is a 
great example of eco-living. This Madrid-based project generates three times the energy it consumes and also houses an orchard in order to produce food. The shape of this house was dictated by its purpose: a sustainable, self-sufficient construction whose "form follows energy". All the characteristics of its environment were carefully studied and taken advantage of, such as the wind and sunlight. the solar rays.

\section{The data analysis process and proposition}

After identifying and explaining the three abovementioned cases, the authors collected qualitative information and data about the practice cases' business model from both sources retrievable on each company website, articles and special issues.

The companies analyzed originally offer services that are involved in all the phases of the innovative process, from the concept to the distribution where prototyping and materializing concepts are used to provide input and feedback on the quality and characteristics of products. By materializing objects, such organizations provide corporate designers and R\&D offices with the input and the insight that they need for the revision of the engineering and conceptualization phases of their process, thus strengthening the relationship between "thought" and "practice" which is typical of creative processes (Shon, 1984).

3-D printing is among the spectrum of technologies that are being developed to make the customized creation of products and parts easier and more cost efficient. The running of a 3-D printer starts from a software technique aimed at helping designers to create three-dimensional shapes on computer screens and then transfer manufacturing instructions to production machines. Such software to make products on this basis is being used in a range of industries from aerospace engines to jewellery. Laser scanning systems - made by companies such as Faro Technologies in the US - can be used to measure the dimensions of items that need to be replicated or modified. Such items could be anything from products or parts made by competitors - in the so-called "reverse engineering" method - to parts of the human body. Information can then be converted into computer codes and sent to a production machine to be made into a solid object.

This new technology is changing a lot of aspects of the manufacturing industry:

- the relationships between designers and production players. The designer will now have the chance not only to do the sketch but also the prototype of the product or, better, the final product as it is shown on the Qurky or Fablab websites. This change will allow designer to acquire a part of the value chain belonging to the manufacturing organization.

- the personalization of the product customization as made possible by Fablab, Quirky or I materialize. A key attribute is that the technology makes it possible to produce "one-off", or highly personalised parts, more easily than other manufacturing methods. This advantage will have an impact on the reduction of the relevance of inventory risk and management connected to the opportunity to 
print the desired artifacts on demand;

- the intrinsic characteristics of 3-D printing technology enable to produce different categories of products in limited quantities and, above all, without any technological complementary relationship among them.

In all of the cases studied, in fact, there exists an extremely high heterogeneity of categories of produced and sellable goods. Fashion accessories, jewels, toys, shoes, musical instruments, lamps, interior design products are indiscriminately found in all product portfolios managed by $3-\mathrm{D}$ printing companies. The major problems connected with this technology concern the range of exploitable materials. The absence of links and technological complementarity among potentially creatable products, together with the absence of production scale and volume economies - as found in several cases, - leads to a wide and heterogeneous management of the product portfolio. The profitability logic is founded on generating profits as well as on a number of product lines with low product volumes (Kekre and Srinivasan, 1990; Osterwalder, and Pigneur, 2010; Amit and Zott, 2001). This characteristic is rooted in the "long tail model" introduced in the first proposition:

1st proposition: the emergence of digital tools for design and manufacturing includes the $3 D$ printer, the laser cutter, the $3 D$ scanner and CAD software and gives rise to a heterogeneous variety of customized and low volume products with no technological complementarities

Based on the development of Web 2. 0 technologies, the advent and the growth of a global creative class (Florida, 2003), and the evolution of a more educated and sophisticated user (Von Hippel, 2009), crowdsourcing represents a new source to manage the innovation process, leveraging on external creative sources and collaboration. As the tools of creation become digital so do the designs which are now just files that can be easily shared online. Makers and organizations can thus take advantage of the web's collaborative innovation, tapping into open source practices and all other social forces that have emerged online. The old model of isolated toil now leaves room to a global movement of people, working together online in a "crowdsourcing collaborative way": crowsourcing is used to connect labor demand and supply (cloud labor), to develop, aggregate and share knowledge and information (collective knowledge), to increase audience engagement and build loyalty through online dialogue with customers (community building) and, finally, to raise capital for new projects and businesses by soliciting contribution from a large number of stakeholders.

A large pool of customers will collectively have virtually unlimited time and energy, an important detail in the long tail model for which capacity needs to be considerably extended (Anderson, 2013). In fact, the increase of the human resource to create and make is shifting away from a focus on a relatively small number of hits (mainstream products and markets ) at the head of the demand curve and moving towards a huge number of niches in the tail (Anderson, 2006). Fablab, Quirky and Imaterialize represent an example of producing different category of commodities as 
art, fashion, gadgets, games, jewelry, toys, etc.... The capability of producing different products for different niches thanks to the costumers that "do the job" has been turning unprofitable products and markets into profitable ones.

Platforms like Quirky gather, collect and sell ideas and concepts that are posted there by external designers and consumers.

These platforms are mainly supported by two types of makers: (i) designers who propose their own products to market them on the platform (market-oriented designers); (ii) users looking for products that are not standardized or sold in great volumes, or in an industrial scale (customization-driven users).

These new customers are deeply influencing the world of manufacturing through forms of self-productions and are creating a "making culture", where users with different tools and technology (among these the 3-D printing technology) are able to build up products for their own consumption and are driven by their interest in new forms of craftsmanship (Friedman, 2010; Senneth, 2009; Micelli, 2011; Yair et al., 1999):

We therefore suggest the following second proposition:

2nd proposition: the new business model organization is identifying in the "makers movement" a profitable productportfolio made of a large and heterogeneous variety of customized and low volume products with no technological complementarity

Furthermore, this model not only increases the number of the products sold and the niches discovered but also boosts collaborative behavior between the member of the community and the organization. For example, Quirky has 8 designers on staff for a total of 40 people in the team, and hundreds of community members that interact with the platform; the ideas submitted receive more than one evaluation both from the community and staff members (both in Quirky, and I materialize). This collaboration involves customers in a new business model where the customers actively participate with the organization in solving his/her need and problems.

The essence of a business model defining the ways in which an enterprise delivers value to customers, entices customers to pay for value and converts those payments to profit no longer reflects the management's hypothesis about what customers might want, how they want it, and how the enterprise can best organize to meet those needs, get paid for doing so, and make a profit but, rather, the suggestions that come from the collaboration between makers and organizations. In this collaboration the organization supports and participates in the makers' process of creating, developing and producing their ownideas. The customer is not only involved in the creation and production but also in the profit share. Users who give design advice on the product idea, the brand name, packaging and so on will receive a percentage of the $30 \%$ profit generated by that specific product idea. Obviosuly, he actual designer of the product will get a share of the profits, once the product has made actual sales. To lower risk, Quirky will only start to produce and sell a product in their webshop, once 500 people have made a pre-sale of it. 
The availability of the organization's tools of production (as the tool to draw and produce the object) improves the time of production and minimizes its odds. For example, Fab-lab lends 3-D printing (and other technological devices) to those inventors who can prove their ability, or who have been educated to use these technologies properly by the Fab Lab Academy. Quirky, I-materialize and Fablab offer digital fabrication as a service so anyone can effectively rent time on highend industrial 3D printers or computer controlling milling machines. Quirky and i. Materialize produce using their own 3D printer or hire them. This form of collaboration introduces the last proposition:

$3^{\text {rd }}$ proposition: the most important resource in the business model of the digital organization is crowdsourcing collaboration that has improved profit potential for both the organization and makers.

Inventing something new is not enough. A new product should also reach the market too, and ideally in a large quantity. This means mass production, which has traditionally been reserved to people who either own a factory or can afford to outsource services. That used to involve months or years of negotiations with different countries and culture. Nowadays, instead, the global factory is increasingly accessible on the web, open to orders of any size from anyone at any scale. Thanks to digital production and design, factories in China are flexible enough to take order online by credit card in small as well as large quantities.

Finally, it should be mentioned that acceleration of production is also sustained by ecommerce in distribution.

\section{Discussion and conclusion}

The business model that comes out from the analysis is one that caters for different types of users that have become designers and makers of small quantities of different products and sells to a limited number of customers thanks to digital platforms such as Quirky and i. Materialize. The underpinning process regarding idea creation is based on a collaborative community that develops ideas into objects thanks to design software, digital technology and community feedback.

The new model centers on the open innovation model while the long tail model sums both the open business model and the long tail model. The demise of the conception-conceptualization-engineering-production-sales activities chain of business processes and the breakdown of integrated value chains (Porter, 1980) has given rise to companies specialized in micro-activities and, above all, to a number of "knowledge brokers" and "bridging ties" that link actors who propose new knowledge in the form of new ideas and products with actors who are able to accomplish, implement and sell these same ideas and products. This business model supported by the new digital technology and in general the improvement of the technology that enables company to carry far more product items in their catalogs, 
(because most of the items exist solely as descriptions in an electronic databases and are digitally distributed) permit to define the long tail model too: as Anderson argues (2006): "the mass of niche has always existed but the cost of reaching it falls now".

Since the first industrial revolution the power to make things in scale has belonged to those who own the means of production, which has meant big factories, big companies and the mass-market goods they manufactured (Anderson, 2013). Now, however, we can imagine an open long tail model where digital instruments distribute community-shared objects: consumers find niche products, niche products find consumers (Anderson, 2006), while consumers create niche products for other consumers.

This impact of this transformation will create an era of unprecedented choice for consumers and organizations together that collaborate to increase their opportunities and profit (Micelli and Rullani, 2011). All this process is creating an emergent business model that makes possible a bottom-up transformation of manufacturing, following the democratization of its trajectory. Though we are still in the early days, the potential is immense because manufacturing is one of the biggest industries in the world (Anderson, 2006).

This new niche market is not replacing the market of hits, but just sharing the stage, as the new business model of the digital organization is redefining the ways in which we design, buy and distribute products.

Future research will hopefully deepen the knowledge surrounding new roles and functions of customers in innovative companies and their open long tail business models. A further investigation could strengthen the insights here summarized by carrying out a quantitative analysis on a wider case sample.

Moreover, extending the research questions and the framework of this study to other fast-paced design industries, e. g., the fashion industry, where the evolution of the product language and meanings is particularly fast, could provide additional findings about the logic of customer engagement in business model innovation.

Finally, the fast emergence of fashion and the changing role of distribution within the fashion industry could provide additional rules for customer engagement and rich new insights about relationship-based business model innovation.

\section{References}

ABECASSIS-MOEDAS C., MAHMOUD-JOUINI S.B., DELL'ERA C., MANCEAU D., VERGANTI R. (2012), "Key Resources and Internationalization Modes of Creative Knowledge-Intensive Business Services: The Case of Design Consultancies, Creativity and Innovation Management" (Online Version of Record published before inclusion in an issue).

AHUJA G. (2000), "Collaboration networks, structural holes and innovation: a longitudinal study", Administrative Science Quarterly, vol. 45, n. 3, pp. 425-455.

AMIT R., ZOTT C. (2001), "Value creation in E-business", Strategic Management Journal, vol. 22, n. 6-7, pp. 493-520. 
ANDERSON C. (2006), The Long Tail: Why the Future of Business Is Selling Less of More, Hyperion, New York.

ANDERSON C. (2013), "Maker movement", Wired, May.

BAUM J.A.C., CALABRESE T., SILVERMAN B.S. (2000), "Don't go it alone: Alliance network composition and startups' performance in Canadian biotechnology", Strategic Management Journal, vol. 21, n. 23, pp. 267-294.

BAUM J. A. C. , OLIVER C. (1991), "Institutional linkages and organisational mortality", Administrative Science Quarterly, vol. 36, n. 2, pp. 187-218.

BINDER T., BRANDT E. (2008), The Design: Lab as platform in participatory design research. CoDesign, vol. 4, n. 2, pp. 75-92.

CHESBROUGH H., (2006a), Open Business Models: How to Thrive in the New Innovation Landscape, Harvard Business School Press, Cambridge (MA).

CHESBROUGH H., (2006b), "New puzzles and new findings", in Chesbrough H., Vanhaverbeke W., West J. (Eds), Open Innovation: Researching a New Paradigm, Oxford University Press, Oxford.

CHESBROUGH H., SCHWARTZ K. (2007), "Innovating business models with codevelopment partnerships", Research-Technology Management, vol. 50, n. 1, pp. 5559.

EDMONDSON A.C., BOHMER R.M., PISANO G.P. (2001), "Disrupted routines: Team learning and new technology implementation in hospitals", Administrative Science Quarterly, vol. 46, n. 4, pp. 685-716.

EHN P. (2005), "Participation in Interaction Design: Actors and Artifacts in Interaction" in Bagnara S. , Crampton Smith J. (eds), Theories and Practices in Interaction Design, Laurence Erlbaum Associates, London.

EISENHARDT K.M. (1989a), "Making fast strategic decisions in high-velocity environments", Academy of Management Journal, vol. 32, n. 3, pp. 543-576.

EISENHARDT K.M. (1989b), "Building theories from case study research", Academy of Management Review, vol. 14, n. 4, pp. 532-550.

EISENHARDT K.M. (1991), "Better stories and better constructs: The case for rigor and comparative logic", Academy of Management Review, vol. 16, n. 3, pp. 620-627.

EISENHARDT K.M., GRAEBNER M.E. (2007), "Theory building from cases: opportunities and Challenges", Academy of Management Journal, vol. 50, n. 1, pp. 25-32.

FLORIDA R. (2003), "Cities and the Creative Class", City \& Community, vol. 2, n. 1, pp. 319.

FRIEDMAN T.L. (2010), "Average is over”, International Herald Tribune, 25 October.

GALUNIC D.C., EISENHARDT K.M. (2001), "Architectural innovation and modular corporate forms", Academy of Management Journal, n. 44, pp. 1229-1249.

GILBERT C.G. (2005), "Unbundling the structure of inertia: Resource versus routine rigidity", Academy of Management Journal, n. 48, pp. 741-763.

HAGEDOORN J., SCHAKENRAAD J. (1994), "The effect of strategic technology alliances on company performance", Strategic Management Journal, vol. 15, n. 4, pp. 291-309.

JOHNSON M.W., CHRISTENSEN C.M., KAGERMANN H. (2008), "Reinventing your business model", Harvard Business Review, vol. 86, n. 12, pp. 59-67.

KEKRE S., SRINIVASAN K. (1990), "Broader Product Line: A Necessity to Achieve Success?", Management Science, vol. 36, n. 10, pp. 1216-1231.

MCKELVEY M. (2001), "The Economic Dynamics Of Software: Three Competing Business Models Exemplified Through Microsoft, Netscape And Linux", Economics of Innovation and New Technology, vol. 10, n, 2-3, pp. 199-236.

MICELLI S. (2011), Futuro Artigiano, L'innovazione nelle mani degli Italiani, Marsilio. 
MICELLI S., RULLANI E. (2011), "Idee motrici, intelligenza personale, spazio metropolitano: tre proposte per il nuovo Made in Italy nell'economia globale di oggi", Sinergie, n. 84, Gennaio-Aprile

MINTZBERG H. (1979), "An emerging strategy of "direct” research", Administrative science quarterly, vol. 24, n. 4, pp. 582-589.

MINTZBERG H., WATERS J.A. (1982), “Tracking strategy in an entrepreneurial firm”, Academy of Management Journal, vol. 25, n. 3, pp. 465-499.

OSTERWALDER A., PIGNEUR Y. (2010), Business Model Generation, Wiley, Hoboken, New Jersey.

PETTIGREW A. (1988), "Longitudinal field research on change: Theory and practice". Paper presented at the National Science Foundation Conference on Longitudinal Research Methods in Organizations, Austin.

PISANO G.P., VERGANTI R. (2008), "Which Kind of Collaboration is Right for You?", Harvard Business Review, vol. 86, n. 12, pp. 78-86.

PORTER M.E. (1980), Competitive Strategy, The Free Press, New York.

POWELL W.W., KOPUT K.W., SMITH-DOERR L. (1996), "Interorganisational collaboration and the locus of innovation: networks of learning in biotechnology", Administrative Science Quarterly, vol. 41, n. 1, March, pp. 116-45.

PRAHALAD C.K., RAMASWAMY V. (2004), The future of Competition, Co-creating Unique Value with Customers, Harvard Business School Press.

SANDERSON S., UZUMERI M. (1995), "Managing product families: The case of the Sony Walkman", Research Policy, vol. 24, n. 5, pp. 761-782.

SENNETH R. (2009), The Craftsman, Yale University Press, 1 edition, New Haven, London.

SHAN W., WALKER G., KOGUT B. (1994), "Interfirm cooperation and startup innovation in the biotechnology industry", Strategic Management Journal, vol. 15, n. 5, pp. 387 94

SHON D.A. (1984), The Reflective Practitioner: How Professionals Think In Action, Basic Books ( ${ }^{\text {st }}$ Edition).

SIGGELKOW N. (2007), "Persuasion with case studies", Academy of Management Journal, n. 50, pp. 20-24.

STUART T.E. (2000), "Interorganizational alliances and the performance of firms: a study of growth and innovation rates in high-technology industry", Strategic Management Journal, vol. 21, n. 8, pp. 791-811.

VON HIPPEL E. (2009), "Democratizing innovation: the evolving phenomenon of user innovation”, International Journal of Innovation Science, vol. 1, n. 1, pp. 29-40.

YAIR K., TOMES A., PRESS M. (1999), "Design through making: crafts knowledge as facilitator to collaborative new product development", Design Studies, vol. 20, n. 6, pp. 495-515.

YIN R.K. (1994), Case study research: Design and methods (2nd ed. ), Sage, Newbury Park, CA.

YIN R.K. (2008), Case study research: Design and methods. Vol. 5, Sage Publications, Incorporated. 
